University of Nebraska - Lincoln

DigitalCommons@University of Nebraska - Lincoln

USDA National Wildlife Research Center - Staff Publications
U.S. Department of Agriculture: Animal and Plant Health Inspection Service

March 2001

\title{
Repelling sandhill cranes from corn: whole-kernel experiments with captive birds
}

\author{
Bradley F. Blackwell \\ USDA/APHIS/WS National Wildlife Research Center, bradley.f.blackwell@aphis.usda.gov \\ David A. Helon \\ U.S. Department of Agriculture, National Wildlife Research Center \\ Richard A. Dolbeer \\ U.S. Department of Agriculture, National Wildlife Research Center
}

Follow this and additional works at: https://digitalcommons.unl.edu/icwdm_usdanwrc

Part of the Environmental Sciences Commons

Blackwell, Bradley F.; Helon, David A.; and Dolbeer, Richard A., "Repelling sandhill cranes from corn: wholekernel experiments with captive birds" (2001). USDA National Wildlife Research Center - Staff

Publications. 526.

https://digitalcommons.unl.edu/icwdm_usdanwrc/526

This Article is brought to you for free and open access by the U.S. Department of Agriculture: Animal and Plant Health Inspection Service at DigitalCommons@University of Nebraska - Lincoln. It has been accepted for inclusion in USDA National Wildlife Research Center - Staff Publications by an authorized administrator of DigitalCommons@University of Nebraska - Lincoln. 


\title{
Repelling sandhill cranes from corn: whole-kernel experiments with captive birds
}

\author{
Bradley F. Blackwell*, David A. Helon, Richard A. Dolbeer \\ U.S. Department of Agriculture, National Wildlife Research Center, Ohio Field Station, 6100 Columbus Avenue, Sandusky, OH 44870, USA
}

Received 12 January 2000; received in revised form 5 April 2000; accepted 7 April 2000

\begin{abstract}
Sandhill cranes (Grus canadensis) are opportunistic omnivores that incorporate both waste and unharvested cereal grains (Gramineae) in their diets. Limited hunting of cranes to reduce crop damage has had questionable results, and lethal control of depredating species is increasingly contentious. Our objectives were to evaluate anthraquinone-based Flight Control ${ }^{\mathrm{TM}}$ and methyl anthranilate-based ReJeX-iT ${ }^{\mathrm{TM}}$ AG-36 as nontoxic avian foraging repellents in separate 2-choice pen tests with captive greater sandhill cranes (G. c. tabida) fed with whole-kernel corn (Zea mays). In both tests, crane pairs consumed, respectively, 8.6 and 9.8 times more untreated than treated corn. Total corn consumption did not differ among the treatment and control groups during the 8-day experiment. Though both repellents were effective at deterring cranes from treated corn, neither has been tested on corn under field conditions. Published by Elsevier Science Ltd.
\end{abstract}

Keywords: Anthraquinone; Flight Control ${ }^{\mathrm{TM}}$; Grus canadensis; Methyl anthranilate; ReJeX-iT ${ }^{\mathrm{TM}}$ AG-36; Repellent; Sandhill crane

\section{Introduction}

Sandhill cranes (Grus canadensis) are opportunistic and ominivorous, and forage on both wild foods and in agricultural settings (Mullins and Bizeau, 1978). In USA and Canada, crane use of crops, particularly cereal grains (Gramineae), has included both post-harvest waste grains (Reinecke and Krapu, 1986; Iverson et al., 1987; Sugden et al., 1988; Sparling and Krapu, 1994) as well as unharvested crops (Stephen, 1967; Knittle and Porter, 1988; McIvor and Conover, 1994). From 1992 to 1996 the U.S. Department of Agriculture (USDA) and Wildlife Services program (WS) received 670 reports pertaining to nuisance or depredating cranes (G. c. tabida) in Wiscon$\sin (72.4 \%$ related to crane damage to corn), with reported damages exceeding $\$ 80,000$ (S. Beckerman, WS, Waupun, Wisconsin, unpublished data).

Hunting has had questionable effects in reducing crop damage by cranes (Stephen, 1967; Sugden et al., 1988; McIvor and Conover, 1994) and opposition to lethal control of depredating species is increasing (Dolbeer,

\footnotetext{
*Corresponding author. Tel.: + 1-419-625-0242; fax: + 1-419-6258464.

E-mail address: bradley.f.blackwell@usda.gov (B.F. Blackwell).
}

1998). However, crop depredation (prior to or during the seedling stage) may be reduced by the use of a nontoxic avian foraging repellent for seeds. Two avian repellents with low toxicity, anthraquinone (AQ)-based Flight Control $^{\mathrm{TM}}$ (FC; Environmental Biocontrol International [EBI], Wilmington, Delaware, USA) and methyl anthranilate (MA)-based formulation, ReJeX-iT ${ }^{\mathrm{TM}}$ AG-36 (RJX; RJ Advantage, Cincinnati, Ohio, USA), may serve as nontoxic seed treatments. Previous work has shown AQ or AQ-based formulations to be effective in repelling birds from seed (Meanley et al., 1956; Royall and Neff, 1961; Avery et al., 1997; Avery et al., 1998; Dolbeer et al., 1998). Avian species consuming AQ for the first time typically exhibit no immediate aversion, but are subsequently repelled (Avery et al., 1997; Dolbeer et al., 1998; Blackwell et al., 1999) due to a suspected post-ingestional response (see review by Avery et al., 1997). Currently, FC is the only AQ-based product registered with the U.S. Environmental Protection Agency (EPA) as an avian repellent (Reg. No. 69969-1; general-use turf treatment against geese). Flight Control contains AQ (50\%, active ingredient [a.i.]), surfactants (2\%), and a latex-based filler $(48 \%)$. The chemical is a light tan liquid, miscible in water, and has a $\mathrm{pH}$ of 7.5-8.5. The oral and dermal $\mathrm{LD}_{50}$ for rats is $>10,000$ and $1000 \mathrm{mg} / \mathrm{kg}$, respectively, (FC Material Safety Data Sheet, EBI). 
ReJeX-iT AG-36 is also registered as an avian repellent (EPA Reg. No. 58035-9). The active ingredient, MA $(14.5 \%)$, is a naturally occurring flavorant, included in the Generally Recognized As Safe list (GRAS; 21Code of Federal Regulations 182.60) of the U.S. Food and Drug Administration and, thus, exhibits low toxicity (e.g., $\mathrm{LD}_{50}=2250 \mathrm{mg} / \mathrm{kg}$ for bobwhite quail [Colinus virginianus]; RJ Advantage unpublished data). The chemical is a purple liquid that also comprises inert ingredients (85.5\%) (RJX Material Safety Data Sheet, RJ Advantage). The oral $\mathrm{LD}_{50}$ for rats is $>5000 \mathrm{mg} / \mathrm{kg}$; RJX is not considered corrosive or sensitizing (RJX Material Safety Data Sheet, RJ Advantage). Although not presently marketed as a seed treatment, MA has exhibited repellent properties with several avian species (Mason et al., 1991; Cummings et al., 1995a; Cummings et al., 1995b; Avery et al., 1995; Belant et al., 1995).

Neither FC nor RJX has been tested on sandhill cranes. We evaluated these candidate repellents separately as treatments for whole-kernel corn in 2-choice pentests with captive sandhill cranes.

\section{Methods}

We conducted the study at the crane-rearing facility at Patuxent Wildlife Research Center (PWRC), Laurel, Maryland, from 19 to 26 October 1998. At PWRC sandhill cranes serve as surrogate incubators for eggs of endangered whooping cranes (G. americana). Crane pairs were held in 9.1-×18.3-, 9.1- $\times 24.4-$, or $10.4-\times 18.3-\mathrm{m}$ pens constructed $2.3-2.6-\mathrm{m}$ high chain link fencing. Each pen area consisted predominantly of grass and included a tree or a structure for shade, a three-sided wood or corrugated steel shelter with a sand base (which also served as a dry area for food provision), and a continuously flowing water system (Swengel and Besser, 1996). Three groups of pens (ranging from 20-54 pens) were used, with group locations differing slightly in elevation and proximity to woodlots and water bodies. Test pairs were maintained as 1 pair per pen and separated by at least 1 pen. The pens were not designed for behavioral observations or experiments requiring controlled microclimate conditions. Prior to the study, crane pairs were provided a maintenance diet (Swengel and Carpenter, 1996) with whole-kernel corn offered occasionally. Although cranes were held in outdoor pens, rodent, insect, and plant foods available within the pens were considered to have provided little to their daily maintenance needs (G.F. Gee, PWRC, personal communication).

Eighteen pairs of sandhill cranes were randomly selected for use in 2-choice (12 pairs) tests and as a control (6 pairs) group for monitoring change in body mass. The twelve 2-choice pairs were randomly assigned to 1 of the two test groups, one receiving FC (6 pairs) and the other receiving RJX (6 pairs). On day one of the experiment, between 0900 and $1000 \mathrm{~h}$, each crane was weighed to the nearest $0.01 \mathrm{~kg}$ (using a $10 \mathrm{~kg}$ Pesola spring scale). On days $1-4$, each pair in the 2-choice test was provided two $20-\mathrm{cm}$ diameter pans, each containing $400 \mathrm{~g}$ of wholekernel corn; control pairs received one pan containing $400 \mathrm{~g}$ of corn. Results of Reinecke and Krapu's (1986) simulation of maximum daily energy requirements for lesser (G. c. canadensis) and greater sandhill cranes in Nebraska (around mid March) indicated that $<200 \mathrm{~g}$ corn per individual was sufficient. Pans were mounted on the wall of the shelter, $1 \mathrm{~m}$ apart and $43 \mathrm{~cm}$ above the floor, to reduce rodent access to the corn (detected on day one, prior to using wall mounts, but with minimal loss of corn). For the next three days, pans were removed from 1700 to $1800 \mathrm{~h}$. No food was provided overnight. Contents of removed pans, including spillage, were weighed to determine consumption. This procedure was repeated on test days 5-8, except that 2-choice pairs received one pan containing $400 \mathrm{~g}$ of untreated corn and another pan with $400 \mathrm{~g}$ of corn mixed (inside sealed plastic containers) with $0.5 \% \mathrm{~g} / \mathrm{g} \mathrm{FC}(0.25 \%$ a.i.; see Dolbeer et al., 1998) or RJX (0.07\% a.i.). We note that Avery et al. (1995) reported effective repellence of redwinged blackbirds (Agelaius phoeniceus) from rice (Oryza sativa) treated with $1 \% \mathrm{~g} / \mathrm{g}$ MA. However, because a comparison between candidate repellents (e.g., based on $\% \mathrm{~g} / \mathrm{g}$ a.i.) was not our objective, we chose to apply RJX at a product level consistent with the $\mathrm{FC}$ treatment. Positions of pans were randomized each day. Each crane was reweighed at the end of the test. The National Wildlife Research Center and PWRC Animal Care and Use Committees approved procedures involving the cranes.

For each separate 2-choice test, we evaluated corn consumption between pans for the four treatment days (i.e., days 5-8) using a one-way repeated measures analysis of variance (ANOVA) (SAS, 1988). Because the six control pairs also provided the standard for corn consumption during the eight days, we evaluated total corn consumption among the groups (i.e., 2-choice pairs receiving FC or RJX, and the control pairs) over the eight days, again using a one-way repeated measures ANOVA. As an index of condition of the crane pairs before and after the tests, we compared the initial and final mean body mass per pair among the groups (control, FC, and RJX) using a one way repeated measures ANOVA. Change in mean body mass per pair (within each group) over the eight days was evaluated using a paired $t$-test.

\section{Results}

During treatment days 5 to 8 , crane pairs in the $\mathrm{FC}$ and RJX tests consumed on average 8.6-9.8 times more untreated than treated corn (FC: $F=72.1 ; 1,10$ d.f.; $P=0.0001$; RJX: $F=91.6 ; 1,10$ d.f.; $P=0.0001)$. Pairs in the FC test consumed a mean $227.5 \mathrm{~g}(\mathrm{SE}=57.5)$ of 
untreated and $26.4 \mathrm{~g}(\mathrm{SE}=7.8)$ of treated corn per day. Pairs in the RJX test consumed a mean $231.4 \mathrm{~g}$ $(\mathrm{SE}=52.6)$ of untreated and $23.6 \mathrm{~g}(\mathrm{SE}=7.8)$ of treated corn per day. All three groups (control, FC and RJX) consumed on average 1.6-2.1 times more corn (total consumption) during treatment days 5-8 than during the pre-treatment period (days 1-4). Total daily corn consumption, however, did not differ $(F=0.07 ; 2,15$ d.f.; $P=0.932$ ) among treatment and control groups over the eight days.

Among the three groups, mean body mass per pair did not differ on day 1 or $8(F=0.09 ; 2,15$ d.f.; $P=0.912)$. Over the eight days, however, mean body mass per pair decreased in the two treatment groups (FC: $5.02-4.78 \mathrm{~kg}$; $t=6.1 ; 5$ d.f.; $P=0.002$; MA: $4.88-4.73 \mathrm{~kg} ; t=3.5 ; 5$ d.f.; $P=0.017)$. In the control group, there was no difference in the change in mean body mass per pair over the eight days $(4.97-4.86 \mathrm{~kg} ; t=1.8 ; 5$ d.f.; $P=0.13)$.

\section{Discussion}

The development of nontoxic repellents accepted within the EPA margins for ecotoxicity (including effects on non-target organisms) is important for mitigating wildlife damage to agriculture without using lethal means. Currently, no effective avian foraging repellent available meets both standards and is registered with the EPA for use on seeds.

In this study, we demonstrated that both FC and RJX were effective at deterring cranes from treated wholekernel corn during separate 4-day pen tests, when untreated corn was readily available. Cranes consumed 8.6 times more untreated than FC-treated corn, and 9.8 times more untreated than RJX-treated corn. In addition, consumption of either repellent did not result in reduced overall food intake, as has been seen in other studies (Avery et al., 1997; Dolbeer et al., 1998). Instead, mean intake increased during the treatment period and no difference was observed in overall corn consumption (over four pre-treatment and four treatment days) among the 2-choice and control pairs. Also, during the 8-day period, no crane pair consumed an entire $400 \mathrm{~g}$ ration. We suspect that the lower food intake (in each of the three groups) during pre-treatment days 1-4 was due to stress associated with change in routine, diet and the presence of new personnel (i.e., the authors).

The subsequent loss of body mass among 2-choice pairs may have been due to stress associated with the introduction of repellents to captive birds or a physiological response due to consumption of the repellents (see Dolbeer et al. 1998). However, there is no evidence of a physiological effect on birds consuming RJX. Moreover, because corn consumption increased across groups during days 5-8 and no differences were detected among groups in total mean daily corn consumption, an explanation for the loss of body mass remains unclear.

In summary, both chemicals were effective in repelling cranes from treated whole-kernel corn in 2-choice tests. Further, both chemicals have shown promise as seed treatments in previous research (see Avery et al., 1995 [RJX]; Avery et al., 1997, 1998; Dolbeer et al., 1998 $[\mathrm{FC}])$. However, neither FC nor RJX has been tested as a seed treatment for corn under field conditions. Currently, the FC label specifies the chemical for turf application only and, thus, an experimental application of FC to seed corn would require an EPA special use permit. In addition, the active ingredient in RJX, MA, is considered very susceptible to microbial degradation (Cummings et al., 1995a, b). Also, though the active ingredient in FC, AQ, has been shown to be repellent to Canada geese 22 days after turf application (Blackwell et al., 1999), degradation rates in soil are speculative $(70 \%$ over 28 days; EBI unpublished data).

\section{Acknowledgements}

Primary funding for this research was provided by the International Crane Foundation, Baraboo, Wisconsin. We also thank George F. Gee, PWRC, for providing cranes, facilities, and personnel to assist with this project. M.L. Avery, S.C. Barras, J. Barzen, J.L. Cummings, D.H. Johnson, F.A. Servello and D. York reviewed earlier drafts of the manuscript.

\section{References}

Avery, M.L., Decker, D.G., Humphrey, J.S., Aronov, E., Linscombe, S.D., Way, M.O., 1995. Methyl anthranilate as a rice seed treatment to deter birds. J. Wildl. Manage. 59, 50-56.

Avery, M.L., Humphrey, J.S., Decker, D.G., 1997. Feeding deterrence of anthraquinone, anthracene and anthrone to rice-eating birds. J. Wildl. Manage. 61, 1359-1365.

Avery, M.L., Humphrey, J.S., Primus, T.M., Decker, D.G., McGrane, A.P., 1998. Anthraquinone protects rice seed from birds. Crop Protect. 17, 225-230.

Belant, J.L., Gabrey, S.W., Dolbeer, R.A., Seamans, T.W., 1995. Methyl anthranilate formulations repel gulls and mallards from water. Crop Protect. 14, 171-175.

Blackwell, B.F., Seamans, T.W., Dolbeer, R.A., 1999. Plant growth regulator (Stronghold ${ }^{\mathrm{TM}}$ ) enhances repellency of anthraquinone formulation (Flight Control $^{\mathrm{TM}}$ ) to Canada geese. J. Wildl. Manage. 63, 1336-1343.

Cummings, J.L., Avery, M.L., Pochop, P.A., Davis Jr., J.E., Decker, D.G., Krupa, H.W., Johnson, J.W., 1995a. Evaluation of a methyl anthranilate formulation for reducing bird damage to blueberries. Crop Protect. 14, 257-259.

Cummings, J.L., Pochop, P.A., Davis Jr., J.E., Krupa, H.W., 1995 b. Evaluation of ReJeX-iT AG-36 as a Canada goose grazing repellent. J. Wildl. Manage. 59, 47-50.

Dolbeer, R.A., 1998. Population dynamics: the foundation of wildlife damage management for the 21st Century. Proc. Vert. Pest Conf. 18, 2-11. 
Dolbeer, R.A., Seamans, T.W., Blackwell, B.F., Belant, J.L., 1998 Anthraquinone Formulation (Flight $\mathrm{Control}^{\mathrm{TM}}$ ) shows promise as avian feeding repellent. J. Wildl. Manage. 62, 1558-1564.

Iverson, G.C., Vohs, P.A., Tacha, T.C., 1987. Habitat use by mid-continent sandhill cranes during spring migration. J. Wildl. Manage. 51, 448-458.

Knittle, C.E., Porter, R.D., 1988. Waterfowl damage and control methods in ripening grain: an overview. US Dep. of the Interior, Fish and Wildl. Ser. Tech. Rep. 14. Washington, DC, $17 \mathrm{pp}$.

Mason, J.R., Avery, M.L., Glahn, J.F., Otis, D.L., Matteson, R.E., Nelms, C.O., 1991. Evaluation of methyl anthranilate and starchplated dimethyl anthranilate as bird repellent feed additives. J. Wildl. Manage. 55, 182-187.

McIvor, D.E., Conover, M.R., 1994. Impact of greater sandhill cranes foraging on corn and barley crops. Agriculture, Ecosystems and Environment 49, 233-237.

Meanley, B., Mann Jr., W.F., Derr, H.J., 1956. New bird repellents for longleaf seed. US For. Ser. Exp. Station, Southern Forestry Notes 105. New Orleans, LA, 4 pp.

Mullins, W.H., Bizeau E.G., E.G., 1978. Summer food of sandhill cranes in Idaho. Auk 95, 175-178.

Reinecke, K.J., Krapu, G.L., 1986. Feeding ecology of sandhill cranes during spring migration in Nebraska. J. Wildl. Manage. 50, 71-79.
Royall Jr., W.C., Neff, J.A., 1961. Bird repellents for pine seeds in the mid-southern states. Trans North Am. Wildl. Nat. Resour. Conf. 26 , 234-238.

SAS, 1988. SAS/STAT User's guide. Release 6.03. SAS Institute, Cary, NC.

Sparling, D.W., Krapu, G.L., 1994. Communal roosting and foraging behavior of staging sandhill cranes. Wilson Bull. 106, 62-77.

Stephen, W.J., 1967. Bionomics of the sandhill crane. Can. Wildl. Ser. Report Series 2. Ottawa, Ontario, $48 \mathrm{pp}$.

Sugden, L.G., Clark, R.G., Woodsworth, E.J., Greenwood, H., 1988. Use of cereal fields by foraging sandhill cranes in Saskatchewan. J. Appl. Ecol. 25, 111-124.

Swengel, S.R., Besser, R.W., 1996. Facilities. In: Ellis, D.H., Gee, G.F., Mirande, C.M. (Eds.), Cranes: Their Biology, Husbandry, and Conservation. US Department of the Interior, National Biological Service, and the International Crane Foundation, Baraboo, Wisconsin, pp. 253-262.

Swengel, S.R., Carpenter, J.W., 1996. General husbandry. In: Ellis, D.H., Gee, G.F., Mirande, C.M. (Eds.), Cranes: Their Biology, Husbandry, and Conservation. US Department of the Interior, National Biological Service, and the International Crane Foundation, Baraboo, Wisconsin, pp. 31-44. 